Original $\quad$ www.pjkd.com.pk

\title{
Lipid Abnormalities Using Random Sampling In Patients With End Stage Renal Disease On Thrice Weekly Hemodialysis
}

\author{
Shahid Anwar, Alvina Zainab, Sobia Mazhar \\ Department of Nephrology, Fatima Jinnah Medical University, Lahore, Pakistan
}

\begin{abstract}
Background: Cardiovascular disease (CVD) is the leading cause of death in the dialysis population. Among other risk factors abnormalities in lipid metabolism occur in patients with all stages of chronic kidney disease (CKD). The most common dyslipidemia in CKD and dialysis is hypertriglyceridemia, whereas the total cholesterol concentration can be normal or low, perhaps due in part to malnutrition. Although hypertriglyceridemia that occurs in CKD may not significantly increase coronary risk, other changes may contribute to the accelerated atherosclerosis. We tried to find out how many patients in our setup on thrice weekly hemodialysis are suffering from dyslipidemia and whether taking treatment or not.

Methodology: Cross sectional study conducted at dialysis center of Sir Ganga Ram Hospital, Lahore including all seventy patients with ESRD undergoing regular HD three times a week, 4 hours per session. Random blood samples (Non-fasting) were collected before dialysis for lipid profile including serum triglyceride, LDL, HDL and total cholesterol.

Results: Out of 70 patients only $3(4.4 \%)$ patients were on statins for dyslipidemia. Triglycerides were high in 41.4\%, total cholesterol was low in $61.4 \%$, and HDL was low in $34.3 \%$.

Conclusion: Hypertriglyceridemia is major lipid abnormality among hemodialysis patients.
\end{abstract}

Keywords: Lipid abnormalities, hemodialysis, hypertriglyceridemia, chronic kidney disease, cardiovascular mortality, antihyperlipidemic, statins.

\section{Corresponding Author:}

Dr Shahid Anwar FCPS Nephrology

HOD Nephrology

Sir Ganga ram Hospital \& Fatima Jinah Medical College,

Lahore, Pakistan.

Email: nephroshahidanwar73@ hotmail.com

Received: November 12, 2020. Accepted December 21, 2020.

PJKD 2020;4(4):328-31

\section{Introduction}

Cardiovascular disease (CVD) is the leading cause of death in the dialysis population, and accounts for approximately $70 \%$ of all deaths. ${ }^{1}$ Atherosclerosis is accelerated in maintenance dialysis patients, but the cause for this acceleration is incompletely understood and not explained by an increased prevalence of traditional risk factors such as hypertension. Dyslipidemia, defined as abnormalities in the concentration, composition, and metabolism of plasma lipids, is common in patients with CKD in nearly all patients on dialysis. ${ }^{2.5}$ The precise contribution of dyslipidemia to atherosclerosis in dialysis patients is not known.

Other findings that are more common in CKD patients compared with the general population include a lower serum concentration of HDL cholesterol, Elevated serum concentrations of lipoprotein (a), Apo lipoprotein (a), and postprandial chylomicron remnants, and increased oxidation of LDL cholesterol.

The primary finding in CKD and dialysis is hypertriglyceridemia, as approximately 40 to 50 percent of patients with CKD have fasting triglyceride levels greater than $200 \mathrm{mg} / \mathrm{dL}(2.26 \mathrm{mmol} / \mathrm{L}){ }^{7.8}$ The total serum cholesterol concentration is sometimes normal or low, perhaps due in part to malnutrition ${ }^{9}$. Approximately 20 to 30 percent have total serum cholesterol levels greater than $240 \mathrm{mg} / \mathrm{dL}(6.2 \mathrm{mmol} / \mathrm{L})$, and 10 to 45 percent have LDL cholesterol levels greater than $130 \mathrm{mg} / \mathrm{dL}(3.4 \mathrm{mmol} / \mathrm{L})$. Although hypertriglyceridemia that occurs in CKD may not significantly increase coronary risk, other changes may contribute to the accelerated atherosclerosis that is commonly seen. ${ }^{5}$

In the present study we planned to identify patients in our setup on thrice weekly hemodialysis suffering from dyslipidemia and whether such patients are taking treatment for dyslipidemia.

\section{Material \& Methods:}

It was Cross sectional study conducted at dialysis center of Sir Ganga Ram Hospital, Lahore. All Seventy patients with ESRD undergoing regular HD three times a week, 3-4 hours per session, enrolled in dialysis center of SGRH, Lahore were included using convenience 
sampling. Before inclusion, an informed written consent was obtained from each patient after full explanation of the study protocol. Patients were assessed via a designed questionnaire before the start of dialysis as per their age, gender, cause of ESRD, vital signs including body temperature, heart rate, respiratory rate, systolic and diastolic arterial pressure, associated comorbidities (IHD, HTN, DM), active medication history including lipid lowering agents, duration of renal replacement therapy. Blood sample were collected for lipid profile including serum triglyceride, LDL, HDL and total cholesterol, before dialysis and sent to laboratory.

\section{Criteria for diagnosis}

We specified three different categories of total cholesterol, low $<160 \mathrm{mg} / \mathrm{dl}$, desirable $160-200 \mathrm{mg} / \mathrm{dl}$, borderline high $200-239 \mathrm{mg} / \mathrm{dl}$ and high $\geq 240 \mathrm{mg} / \mathrm{dl}$. HDL cholesterol was taken as high if greater than $60 \mathrm{mg} / \mathrm{dl}$, normal if $40-60 \mathrm{mg} / \mathrm{dl}$ and low if less than $40 \mathrm{mg} / \mathrm{dl}$. LDL cholesterol was taken as optimal if less than $100 \mathrm{mg} / \mathrm{dl}$, near optimal if 100-129mg/dl, borderline high if 130-159mg/dl, high if 160$189 \mathrm{mg} / \mathrm{dl}$ and very high if $\geq 190 \mathrm{mg} / \mathrm{dl}$. Triglycerides taken as normal if $<150 \mathrm{mg} / \mathrm{dl}$, borderline high if $150-199 \mathrm{mg} / \mathrm{dl}$, high if 200-499mg/dl, and very high if $\geq 500 \mathrm{mg} / \mathrm{dl}$.

Analysis was performed using the Statistical Package for Social Sciences (SPSS) software volume 17. Student “t” test was performed to correlate the parameters between two normally distributed groups. For independent group analysis, paired t tests were done. A P value of less than 0.05 was considered significant.

\section{Results}

A total number of 70 patients with end-stage renal disease due to any cause on thrice weekly hemodialysis were enrolled in the current study. The baseline characteristics of the patients are shown in table No.1.

\section{Table 1: Baseline characteristics of 70 patients on thrice weekly hemodialysis.}

\begin{tabular}{|c|c|}
\hline Characteristics & Frequency n (\%) \\
\hline Male/female & $46 / 24$ \\
\hline Age (years) & $47.2+13.3$ \\
\hline Known Ischemic Heart Diseaae & 16 \\
\hline Hypertension & 61 \\
\hline Diabetics & 32 \\
\hline Current smoker & 5 \\
\hline Past smoker & 18 \\
\hline $\begin{array}{l}\text { Medication } \\
\text { CCB } \\
\text { B-bloker } \\
\text { K-channel modulator } \\
\text { Alfa-blocker } \\
\text { Amiodrone } \\
\text { Digoxine } \\
\text { Metoclopramide } \\
\text { PPI } \\
\text { Aspirin } \\
\text { Statin } \\
\text { Alfa-blocker }\end{array}$ & $\begin{array}{l}45 \\
8 \\
0 \\
20 \\
0 \\
0 \\
43 \\
57 \\
7 \\
3 \\
20\end{array}$ \\
\hline BMI (Body Mass Index) & $24.6(6.9)$ \\
\hline \multicolumn{2}{|l|}{ Triglycerides } \\
\hline Normal & 41 (58.6) \\
\hline Borderline high & $9(12.9)$ \\
\hline High & $19(27.1)$ \\
\hline Very high & $1(1.4)$ \\
\hline \multicolumn{2}{|l|}{ Total cholesterol } \\
\hline Desirable & $22(31.4)$ \\
\hline Borderline high & $3(4.3)$ \\
\hline High & $2(2.9)$ \\
\hline low & $43(61.4)$ \\
\hline \multicolumn{2}{|l|}{ LDL } \\
\hline Optimal & $48(68.5)$ \\
\hline Near optimal & $15(21.4)$ \\
\hline Borderline high & $7(10)$ \\
\hline \multicolumn{2}{|l|}{$\mathrm{HDL}$} \\
\hline low & $24(34.3)$ \\
\hline Normal & $41(58.6)$ \\
\hline High & $5(7.1)$ \\
\hline
\end{tabular}


Only 3 (4.4\%) patients were on statins for dyslipidemia. Triglycerides were high in 41.4\%, total cholesterol was low in 61.4\%, and HDL was low in $34.3 \%$. Serum triglyceride levels were significantly higher among diabetics than non-diabetics $(\mathrm{P}<0.05)$. While HDL was significantly higher among non-diabetics than diabetics $(\mathrm{P}<0.05)$. The other lipid parameters were relatively higher among diabetics than among non-diabetics although the values did not reach significant levels.

Total cholesterol and LDL were significantly elevated in female patients as compared to male patients $(\mathrm{P}<0.05)$, while HDL was significantly lower in male patients as compared to females $(\mathrm{P}<0.05)$, while no correlation found with triglycerides levels.

Total cholesterol was significantly elevated in patients with past history of IHD as compared to with no past history of ischemic heart disease $(\mathrm{P}<0.05)$. While no correlation of IHD was found with other lipid parameters.

We could not find any significant correlation between deranged lipid profile, hypertension, smoking and duration of dialysis.

\section{Discussion}

According to our study serum triglycerides were elevated in $42 \%$ of hemodialysis patients which is a significant proportion. While total cholesterol was seen below normal range in $61 \%$ of patients and was raised in $7 \%$ of patients. LDL was high in $31 \%$ of hemodialysis patients and HDL was low in $34 \%$ of hemodialysis patients.

Abnormalities in lipid metabolism occur in patients with all stages of chronic kidney disease (CKD). ${ }^{2-8}$ The most common dyslipidemia in CKD and dialysis is hypertriglyceridemia, similar to our results, whereas the total cholesterol concentration can be normal or low, perhaps due in part to malnutrition again noted in our study. In contrast, the nephrotic syndrome is typically associated with hypercholesterolemia and hypertriglyceridemia.

A modest decline in HDL-cholesterol is commonly observed, thereby raising the LDL/HDL cholesterol ratio. ${ }^{10}$ A cross-sectional study demonstrated that, compared with patients who had an estimated glomerular filtration rate (GFR) greater than $60 \mathrm{~mL} \mathrm{~min} / 1.73 \mathrm{~m} 2$, lower levels of GFR were independently associated with decreased serum HDL. ${ }^{11}$

Elevated plasma levels of lipoprotein (a) are present in patients with CKD. ${ }^{12,13}$ Lipoprotein (a) is an LDL-like particle that contains an additional protein, apolipoprotein (a), and may be an independent risk factor for atherosclerosis. Higher levels of post-prandial chylomicron remnants have been described in CKD patients. ${ }^{14}$ Transient exposure of the vascular wall to these atherogenic particles may be deleterious. Patients with CKD have an increase in the oxidative modification of LDL-cholesterol. ${ }^{15}$

In the general population, the serum total cholesterol concentration is a clear risk factor for coronary disease and death from cardiovascular disease, with the risk increasing progressively with higher values for serum total cholesterol. The concentrations of lipid fractions, such as low-density lipoprotein (LDL) and high-density lipoprotein (HDL), are also important. By comparison, studies in patients with CKD or end-stage renal disease are conflicting: some show a relation between higher serum cholesterol levels and mortality risk, especially among patients without signs of malnutrition and inflammation. ${ }^{16-18}$ In some studies low (not high) serum cholesterol values were associated with increased mortality ${ }^{16,17,19,20}$; and others did not find any association between lipid levels and mortality among patients with CKD. ${ }^{16,17,19-}$

${ }^{23}$ The possibly worse prognosis with low serum cholesterol has been thought to reflect the adverse effect of malnutrition and chronic inflammation upon mortality, resulting in a paradoxical risk factor reversal. ${ }^{20,24-26}$ Traditionally, most laboratories have required patients to fast for $9-12$ hours before screening. However, studies have questioned the utility of fasting before lipid panels, and some diagnostic labs routinely accept non-fasting samples. ${ }^{27,28}$

The pathogenesis of most lipid abnormalities in patients with CKD primary involves defective removal from the circulation. The diminished clearance of triglycerides, which can lead to hypertriglyceridemia, stems both from an alteration in the composition of circulating triglycerides (which become enriched with apolipoprotein C-III) and, perhaps later, from reductions in the activity of lipoprotein lipase and hepatic triglyceride lipase which are involved in triglyceride removal. ${ }^{4,526}$ The normal or low total serum cholesterol concentration can be explained due in part to malnutrition. ${ }^{9}$

In our study female patients had higher cholesterol and LDL levels than male patients while HDL level were comparatively more low in male patients. Our finding is similar to the reported by Salman et.al. in non-dialysis CKD patients showing higher HDL in females. ${ }^{12}$

Our study shows that diabetic patients on HD had significantly higher triglycerides than non-diabetics, while HDL, the good cholesterol was also lower in patients with diabetes. In a local study by Maheshwari et.al. similarly, triglycerides were higher among dialysis patients. They did not specify if there was any difference among the diabetics or nondiabetics, nevertheless almost one third of their patients were diabetics. ${ }^{13}$

We did not find any significant correlation between deranged lipid profile, hypertension, smoking and duration of dialysis suggesting survival due to small population size compared to reported by others in larger population. ${ }^{29-31}$

\section{Conclusion:}

In conclusion, Hypertriglyceridemia is major lipid abnormality among hemodialysis patients. There is limited data regarding the goals, efficacy, and safety of treatment for lipid optimization among dialysis patients in our population. No prospective randomized studies have examined the utility of lipid-lowering strategies in this specific patient population. 
Conflict of Interest: All the authors declared no conflict of interest

\section{References:}

1. USRDS. United States Renal Data Systems annual data report. Am J Kidney Dis 2007;49(Supp11):S10-S294.

2. Wheeler DC, Bernard DB. Lipid abnormalities in the nephrotic syndrome: causes, consequences, and treatment. Am J Kidney Dis 1994; $23: 331$.

3. Appel G. Lipid abnormalities in renal disease. Kidney Int 1991; 39:169.

4. Senti M, Romero R, Pedro-Botet J, Pelegri A, Nogues X, Rubies-Prat J.

5. et al. Lipoprotein abnormalities in hyperlipidemic and normolipidemic men on hemodialysis with chronic renal failure. Kidney Int 1992; 41:1394.

6. Attman PO, Samuelsson O, Alaupovic P. Lipoprotein metabolism and renal failure. Am J Kidney Dis 1993; 21:573.

7. Sechi LA, Zingaro L, De Carli S, et al. Increased serum lipoprotein(a) levels in patients with early renal failure. Ann Intern Med 1998; $129: 457$.

8. Afzali B, Haydar AA, Vinen K, Goldsmith DJ. From Finland to fatland: Beneficial effects of statins for patients with chronic kidney disease. J Am Soc Nephrol 2004; 15:2161.

9. Kwan BC, Kronenberg F, Beddhu S, Cheung AK. Lipoprotein metabolism and lipid management in chronic kidney disease. J Am Soc Nephrol 2007; 18:1246.

10. Weiner DE, Sarnak MJ. Managing dyslipidemia in chronic kidney disease. J Gen Intern Med 2004; 19:1045.

11. Seres DS, Strain GW, Hashim SA, Goldberg IJ, Levin NW. Improvement of plasma lipoprotein profiles during high-flux dialysis. J Am Soc Nephrol 1993; 3:1409.

12. Lo JC, Go AS, Chandra M, Fan D, Kaysen GA. GFR, body mass index, and low high-density lipoprotein concentration in adults with and without CKD. Am J Kidney Dis 2007; 50:552.

13. Shafi ST, Saleem M, Anjum R, Abdullah W, Shafi T. Lipid abnormalities in hospitalized patients with chronic kidney disease not on hemodialysis. J Sharif Me Dent Coll 2016;02(1):3-6

14. Maheshwari N, Ansari MN, Laghari MS, Darshana, Lal K, Ahmed K. Pattern of lipid profile in patients on maintenance hemodialysis. Saudi J Kidney Dis Transpl 2010;21(3):565-570.

15. Wilson DE, Chan IF, Cheung AK, Dutz W, Buchi KN. Retinyl ester retention in chronic renal failure. Further evidence for a defect in chylomicron remnant metabolism. Atherosclerosis 1985; 57:189.

16. Maggi E, Bellazzi R, Falaschi F, Frattoni A, Perani G, Finardi G. Enhanced LDL oxidation in uremic patients: an additional mechanism for accelerated atherosclerosis? Kidney Int 1994; 45:876.

17. Liu Y, Coresh J, Eustace JA, Longenecker JC, Jaar B, Fink NE. Association between cholesterol level and mortality in dialysis patients: role of inflammation and malnutrition. JAMA 2004; 291:451.

18. Kilpatrick RD, McAllister CJ, Kovesdy CP, Derose SF, Kopple JD, Kalantar-Zadeh K. Association between serum lipids and survival in hemodialysis patients and impact of race. J Am Soc Nephrol 2007; 18:293.

19. Contreras G, Hu B, Astor BC, Greene T, Erlinger T, Kusek JW. Malnutrition-inflammation modifies the relationship of cholesterol with cardiovascular disease. J Am Soc Nephrol 2010; 21:2131.

20. Iseki K, Yamazato M, Tozawa M, Takishita S. Hypocholesterolemia is a significant predictor of death in a cohort of chronic hemodialysis patients. Kidney Int 2002; 61:1887.

21. Kalantar-Zadeh K, Block G, Humphreys MH, Kopple JD. Reverse epidemiology of cardiovascular risk factors in maintenance dialysis patients. Kidney Int 2003; 63:793.

22. Kovesdy CP, Anderson JE, Kalantar-Zadeh K. Inverse association between lipid levels and mortality in men with chronic kidney disease who are not yet on dialysis: effects of case mix and the malnutrition-inflammation-cachexia syndrome. J Am Soc Nephrol 2007; 18:304.

23. Shlipak MG, Fried LF, Cushman M, Manolio TA, Peterson D, Stehman-Breen C. Cardiovascular mortality risk in chronic kidney disease: comparison of traditional and novel risk factors. JAMA 2005; 293:1737.

24. Chawla V, Greene T, Beck GJ, Kusek JW, Collins AJ, Sarnak MJ, Menon V. Hyperlipidemia and long-term outcomes in nondiabetic chronic kidney disease. Clin J Am Soc Nephrol 2010; 5:1582.

25. Lowrie EG, Lew NL. Death risk in hemodialysis patients: the predictive value of commonly measured variables and an evaluation of death rate differences between facilities. Am J Kidney Dis 1990; 15:458.

26. Degoulet P, Legrain M, Reach I, Aimé F, Devries C, Rojas P. Mortality risk factors in patients treated by chronic hemodialysis. Report of the Diaphane collaborative study. Nephron 1982; 31:103.

27. Arnadottir M, Thysell H, Dallongeville J, Fruchart JC, Nilsson-Ehle P. Evidence that reduced lipoprotein lipase activity is not a primary pathogenetic factor for hypertriglyceridemia in renal failure. Kidney Int 1995; 48:779.

28. Sidhu, D.; Naugler, C. "Fasting Time and Lipid Levels in a Community-Based Population: A Cross-sectional Study / Fasting Time and Lipid Levels". Arch Intern Med 201272 (22): 1 - 4

29. Mora S. "Nonfasting for Routine Lipid Testing: From Evidence to Action". JAMA Intern Med 2016 176 (7): 1005 - 6.

30. Mitwalli AH, Alam AA, Wakee JS, Isnani AC. Dyslipidemia in Dialysis Patients. Saudi J Kidney Dis Transpl 2011;22(4):689-694.

31. Stack AG, Yermak D, Roche DG, Ferguson DP, Elsayed M, Mohammed W et,al. Differential impact of smoking on mortality and kidney transplantation among adult Men and Women undergoing dialysis. BMC Nephrol 2016;17:95. 